\section{O sentimento na música: o sertão nordestino de Luiz Gonzaga em Asa Branca}

Heitor Matos da Silveira

Mais coisas sobre nós mesmos nos ensina a terra Que todos os livros. Por que nos oferece resistência. Ao se medir com um obstáculo o homem aprende a se conhecer; para superá-lo, entretanto, ele precisa de ferramenta.

[...] O camponês, em sua labuta, vai arrancando lentamente

Alguns segredos à natureza; e a verdade que ele obtém é universal

Antoine de Saint-Exupéry (1976)

\section{INTRODUÇÃO}

A Geografia, por muito tempo (e ainda) compõem em sua base científica um racionalismo que afasta o eu e prioriza o objeto, a razão. A surgência de uma geografía voltada para o eu, para o ser no mundo, para entender o homem per si, entender o homem no mundo como parte integrante desse organismo pulsante que vibra e emana signos e símbolos, do ser no "mundo". A essa forma de se fazer geografia, embasada a geograficidade de Dardel (2011) e nas bases fenomenológicas que nascem com Husserl, a Geografia Humanista se torna o campo geográfico que preconiza o estudo do ser no mundo, o homem no mundo, criticando o racionalismo e visando um humanismo.

1 Graduando do curso de Geografia da Universidade Estadual de Londrina (UEL). heitormsilveira@outlook.com.

$\not$ Departamento de Geociências. Centro de Ciências Exatas. Universidade Estadual de Londrina. Rodovia Celso Garcia Cid, PR-445, Km 380, Campus Universitário, Londrina, PR. 86057-970.
Conforme já conotado por Holzer (2010) por muito tempo a obra prima do geógrafo francês Eric Dardel esteve esquecida nas gavetas do tempo perecendo conforme o desenvolvimento científico. Assim, "quando os franceses se deram conta da importância e da riqueza da obra de Dardel para a renovação da geografia, [...] já se haviam passado vinte anos desde a primeira citação de seu livro por geógrafos norteamericanos" (HOLZER, 2010, p. 1). Apesar de não ser um doutor ou mestre em Geografia, Dardel conseguiu atingir a essência geográfica em seu livro, com o conceito de geograficidade, essa relação visceral do homem com a terra.

O advento da Geografía Humanista compôs uma nova forma de fazer geografia. Com as propostas de Dardel (2011) fora possível entender questões de sentimento e pertencimento do ser com o lugar. Nesta, o lugar é considerado o conceito chave. Enquanto o espaço se constituí no desconhecido e sem valores, o lugar é o dotado de valor, de sentimento, pertencimento, de sentimentos de topofilia ou topofobia.

Este lugar, conforme Relph

[...] são os contextos ou panos de fundo para a intencionalidade definir objetos ou eventos, ou seja, eles podem ser objetos da intenção em seu sentido primordial [...] [pois] tida consciência não é meramente consciência de algo, mas de algo em seu lugar, e [...] esses lugares são definidos geralmente em termos dos objetos e de seus significados. Como objetos, no seu verdadeiro sentido, lugares são essencialmente focos de intenção, que têm usualmente uma localização fixa e trações que persistem em uma forma identificável. (RELPH apud HOLZER, 1999, p. 72)

Outras formas de entendimento de lugar foram feitas por Relph (apud HOLZER, 1999, p.72) onde se tem este como identidade.

A identidade refere-se ao espírito, ao sentido, ao gênio do lugar. Ela provém das intenções e experiências intersubjetivas, que resultam da familiaridade (RELPH, 1976), Estas ligações 
que se iniciam com o nosso nascimento e se aprofundam com as experiências (TUAN, 1983), implicam em um conhecimento detalhado do lugar, e na constituição de raízes, de um centro de significados que se torne insubstituível (HOLZER, 1999, p. 72).

É a esta definição de lugar que este pequeno ensaio se embasa, visando expor uma visão fenomenológica à poesia de Luiz Gonzaga, ao seu sentimento de pertencimento construído a partir de uma experiência, que, mesmo com a necessidade de afastamento físico desse lugar, o mesmo continuou enraizado em seu interior, sendo insubstituível. Esse sentimento ao lugar, esse pertencimento ultrapassa as barreiras físicas e as mazelas que o sertão impõe ao ser, se constituindo em uma Topofilia fomentada porTuan (2012).

Esta topofilia se constitui em outra forma de análise de relações com o lugar, este sentimento de afeto com o lugar, de identidade com o topo, conforme Tuan (2012).

\section{AsA Branca, LUIz Gonzaga}

Aqui será exposta a letra inteira da música de Luiz Gonzaga, para que a mesma seja analisada e poetizada, no fim, para que a asa branca possa retornar e repousar no seu lugar, no sertão.

\section{Asa Branca \\ (Luiz Gonzaga)}

Quando olhei a terra ardendo

Qual a fogueira de São João

Eu perguntei a Deus do céu, ai

Por que tamanha judiação

Eu perguntei a Deus do céu, ai

Por que tamanha judiação

Que braseiro, que fornalha

Nem um pé de plantação

Por falta d'água perdi meu gado
Morreu de sede meu alazão

Por farta d'água perdi meu gado

Morreu de sede meu alazão

Até mesmo a asa branca

Bateu asas do sertão

Então eu disse, adeus Rosinha

Guarda contigo meu coração

Então eu disse, adeus Rosinha

Guarda contigo meu coração

Hoje longe, muitas léguas

Numa triste solidão

Espero a chuva cair de novo

Pra mim voltar pro meu sertão

Espero a chuva cair de novo

Pra mim voltar pro meu sertão

Quando o verde dos teus olhos

Se espalhar na prantação

Eu te asseguro não chore não, viu

Que eu voltarei, viu

Meu coração

Eu te asseguro não chore não, viu

Que eu voltarei, viu

Meu coração

Os fragmentos textuais acima grifados transpõem o sentimento de Luiz Gonzaga com o sertão. A chuva que não cai e não faz o seu gado ter vida, que assola o sertão e não permite que ele sobreviva, faz com que o nordestino saia deste lugar, de sua terra, e siga caminho para outro espaço, um espaço não revelado por Gonzaga, pois este não lhe passa afeto, não é dotado de valor, não substitui o sertão que foi o berço do seu nascimento e que nele cresceu. $E$ mesmo com as mazelas do sertão, apenas um pingo de chuva, apenas uma gota de vida fará com que ele volte, e aqui, o sertão é novamente retomado, o seu lugar é novamente colocado em destaque, pois o lugar dotado de sentimento supera qualquer problema.

Ao se referir ao sertão como "meu", uma palavra que expressa o sentido de posse, de pertencimento... o pertencimento... essa posse 
do lugar, com o sertão, com o solo castigado pelos raios solares não se refere, aqui, simplesmente como posse da terra numa maneira de fazer com que a mesma produza e gere renda... não... a posse do sertão, o sertão de Luiz Gonzaga é o seu sertão, é a sua vida, seu sentimento, suas lembranças, suas memórias, suas experiências, suas vivências, suas imaginações, suas paixões... o "meu sertão" aduz um pertencimento com o lugar, aduz uma geograficidade dardeliana que nos permite entender até mesmo o sentimento de outros retirantes das terras negras (blacklands) que sentem em seu espírito guerreiro e batalhador a vontade de voltar até mesmo para as condições mais extremas de sobrevivência humana... pois estes retirantes são sonhadores e amantes... eles detém um sentimento com o lugar que nem sempre é entendido por alguns... um sentimento que faz com que ele enfrente a seca e a fome para estar no cerne de seu sentimento, da sua imaginação, da sua vida, da sua vivência, de seu afeto à terra... que esteja no centro do seu lugar...

As questões vividas por Luiz Gonzaga no sertão apontam para mais uma das muitas análises humanistas que podem ser feitas... pois, se o mesmo retirante que deixa seu lugar para procurar condições melhores de sobrevivência, tem o desejo de retornar ao lugare acaba retornando, independente das condições físicas e sociais que este lugar tenha, é o centro de um estudo geográfico humanista, é o que se entende e o que se busca ao considerar a geograficidade de Eric Dardel como a realidade geográfica... pois o homem, mesmo com esses problemas, consegue se adaptar para estar no seu lugar.

\section{CONSIDERAÇÕES FINAIS}

O sentimento, o amor, a poesia de Gonzaga é uma forma coerente de se entender as questões de lugar e de pertencimento, discutidas assiduamente pela Geografia Humanista.
O homem vivencia e experimenta a terra, a descobre a partir de sua relação carnal e humana com um devido lugar, sente em suas raízes e no seu âmago a necessidade de voltar aquele lugar, de sentir aquele lugar, de rever os signos emanados pela paisagem que compõem este lugar.

Assim como a literatura, colocada e poetizada por Marandola Jr, Lívia de Oliveira, Lúcia Helena Batista Gratão e outros geógrafospoetas (MARANDOLA JR.; GRATÃO, 2010), a música, mesmo que simplória e com poucas letras, consegue ser carregada de sentimentos e de valores, sendo que sua leitura geográfica com olhares humanistas no viés da fenomenologia é possível e necessária, pois o homem não é feito apenas de racionalidade, ele é feito de sentimento, sentimento com a terra, com a água, com o ar... é a esse sentimento à terra, ao lugar, que a Geografia deve buscar nas entranhas da subjetividade humana e entender os olhares que cada ser, cada "eu" tem com um espaço, que podem ser dotados de sentimentos bons ou ruins, por uma topofilia ou topofobia.

\section{REFERÊNCIAS}

DARDEL, Eric. O Homem e a Terra: natureza da realidade geográfica. (Tradução de Werther Holzer) São Paulo: Perspectiva, 2011. 176p.

HOLZER, Werther. A influência de Eric Dardel na construção da Geografia Humanista norte americana. In:XVIENCONTRO NACIONAL DE GEÓGRAFOS, 16, Porto Alegre, 2010. Anais... Porto Alegre: AGB, 2011. p. 1-11.

O lugar na geografia humanista. Revista Território, Rio de Janeiro, v. 4, n. 7, p. 67-78, jul./dez. 1999.

MARANDOLA JR., Eduardo; GRATÃO, Lúcia H. (Orgs.) Geografia e literatura: ensaios sobre geograficidade, poética e imaginação. Londrina: Eduel, 2010. 354p. 